\title{
An Original Tuneable Plasma Process for the Synthesis of Tailored Nanoparticles ${ }^{\dagger}$
}

\author{
Emile Haye 1,2,*, Loris Chavee ${ }^{1,2}$, Florian Bocchese ${ }^{2}$, Yan Busby ${ }^{3}$, Mathieu Da Silva Pires ${ }^{2}$, \\ Laurent Houssiau ${ }^{1}$, Jean-François Colomer ${ }^{4}$, Jean-Jacques Pireaux ${ }^{1}$ and Stéphane Lucas ${ }^{2}$ \\ 1 LISE-NISM, University of Namur, 61 Rue de Bruxelles, 5000 Namur, Belgium \\ 2 LARN-NISM, University of Namur, 61 Rue de Bruxelles, 5000 Namur, Belgium \\ 3 Nanomatériaux Pour Les Systèmes Sous Sollicitations Extrêmes (NS3E), French-German Research Institute \\ of Saint-Louis, 68301 Saint-Louis, France \\ 4 Service de Microscopie Electronique, University of Namur, 61 Rue de Bruxelles, 5000 Namur, Belgium \\ * Correspondence: emile.haye@unamur.be \\ + Presented at the 6th International Electronic Conference on Sensors and Applications, 15-30 November \\ 2019; Available online: https://ecsa-6.sciforum.net/
}

Published: 10 November 2020

\begin{abstract}
A dry process is presented to synthesize nanoparticles on different powder substrates. The process is based on the plasma degradation of solid organometallic precursors mixed with the powder substrate to generate various nanoparticles of $2-15 \mathrm{~nm}$. Compared to conventional wet chemistry, plasma processing offers the advantage of reducing the environmental impact of the synthesis by reducing the energy consumption and relying on a solvent-free and waste-free scalable process. The novelty and high versatility of the process are demonstrated in this work. Choosing the right discharge parameters (pressure, reactive gas, plasma power...), amorphous or crystalline monometallic, bimetallic, oxide, or nitride nanoparticles can be produced, onto inorganic (such as $\mathrm{TiO}_{2}$ ) or carbon-based substrates like graphene, carbon xerogel, or carbon nanotubes. Results have been obtained for various nanoparticles, including transition $(\mathrm{Mn}, \mathrm{Fe}, \mathrm{Ni})$, post-transition $(\mathrm{Zn}, \mathrm{Al})$, and noble metals $(\mathrm{Cu}, \mathrm{Pt}, \mathrm{Pd}, \mathrm{Rh})$. Moreover, the organometallic precursor(s) decomposition and the subsequent nanoparticle synthesis can be monitored in situ using optical emission spectroscopy of the plasma discharge.
\end{abstract}

Keywords: nanoparticles; plasma process; RF-ICP; catalyst

\section{Introduction}

Nanomaterials are now at the heart of a very wide broad of applications. One can cite nanocatalyst for fuel cells, photocatalyst for dye degradation, radiosensitizer for medical application, or plasmonic nanomaterial for biosensors. The current synthesis are mainly based on wet chemistry, involving the extensive use of solvents and/or heat to produce materials. Plasma-based processes bring new perspectives of synthesis: such non-equilibrium processes provide the extreme conditions needed for the synthesis of materials; while being economical and energy-sufficient processes. The conventional methods are too demanding in terms of energy and cost. Among the non-equilibrium processes, the low-pressure plasma discharges are one of the best solutions to create highly reactive and extreme media, while the global conditions are near ambient conditions. Such a non-equilibrium and extreme environment (electron temperature of $\approx 10^{4} \mathrm{~K}$ while the neutral and ions species are at $\approx 300 \mathrm{~K}$ ) is favorable for the synthesis of new-and sometimes, metastable-materials, without the extensive use of solvent and energy as it is required in chemical processes. Besides, the plasma 
discharge emits characteristic lights from the synthesis media that give information on the synthesis mechanisms.

Unfortunately, the reported plasma synthesis using organometallic precursor uses a continuous feeding of the organometallic, via carrier gas (directly a gaseous precursor, or a solid precursor soluted in a solvent that is vaporized in the chamber). It results in the material deposition on undesired surfaces, a possible clogging of feeding pipes, and waste material. In the present work, we present a batch plasma-based process, solely using solid materials. A fixed initial amount of solid organometallic is mixed with a powdery substrate and treated in the plasma chamber. Such methodology limits the waste of material, but most of all offers high versatility as the plasma discharge (reactive gas, pressure, and power) drives the characteristics of the nanoparticles (chemistry, crystallinity, size). Some of the results have been reported in previous works [1-6], mainly based on a carbon substrate. The present work regroups the different approaches and new insights in a single and concise document.

\section{Materials and Methods}

The synthesis of nanoparticles onto the powdery substrate is performed in an inductively coupled radiofrequency plasma (ICP-RF) discharge, working at $13.56 \mathrm{MHz}$. The initial raw materials are metal acetylacetonate from Sigma Aldrich, namely $\mathrm{M}(\mathrm{acac}) \times$ with $\mathrm{M}$ an element such as transition metal (Fe, Ni, Co) post-transition metal ( $\mathrm{Al}, \mathrm{Zn}$ ) or noble metal $(\mathrm{Cu}, \mathrm{Pt}, \mathrm{Pd}, \mathrm{Rh})$. The substrates that have been tested are $\mathrm{TiO}_{2}$ nanopowder (anatase), graphene, carbon nanotube, and carbon xerogel. The initial materials are mixed, set in a Petri box, and introduced into the plasma chamber (Figure 1). The reactor is pumped down to a high vacuum, then the plasma composition is regulated by injecting a controlled flow of gas mixture comprising $\mathrm{Ar}, \mathrm{O}_{2}$, and/or $\mathrm{NH}_{3}$, to reach a working pressure of a few mTorr (from 2 to 50 mTorr). The plasma power is varied between 80 to $200 \mathrm{~W}$, and the treatment is adjusted between 30 to $60 \mathrm{~min}$. Additionally, an optical emission spectroscope (OceanOptics USB 4000 ) is used to monitor the process.

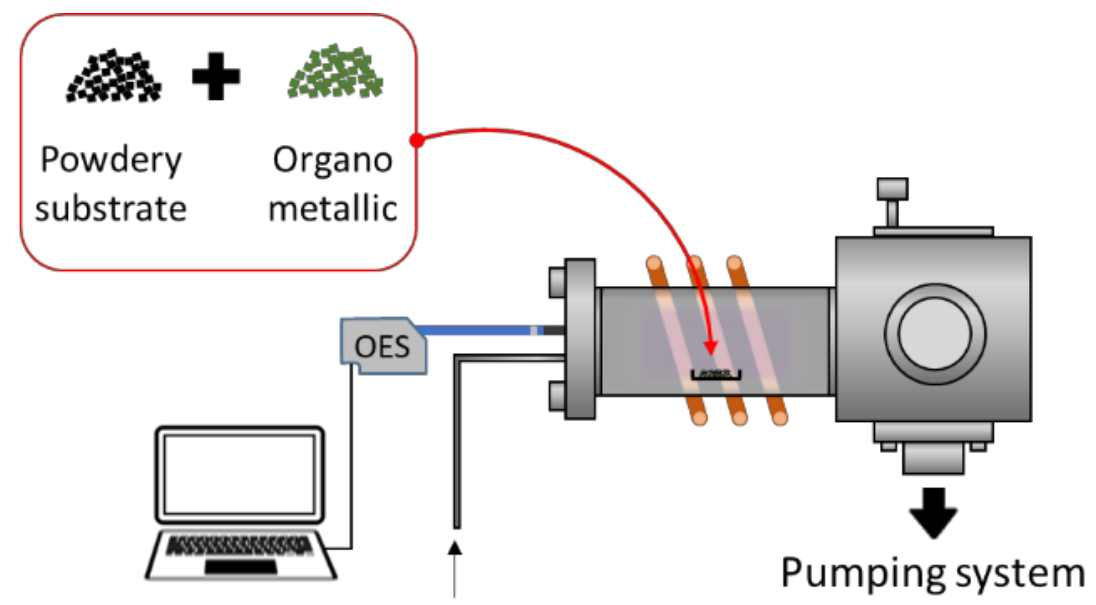

Gas injection

Figure 1. Schematic sketch of the plasma process.

After plasma treatment, the surface chemistry, the morphology, and the crystal structure of the metal nanoparticles have been determined by X-ray photoelectron spectroscopy (XPS, K-Alpha spectrometer by Thermo Scientific), scanning electron microscopy (JEOL 7500F), transmission electron microscopy (TEM, Philips Tecnai 10) and X-ray diffraction (Pananalytical X'pert Pro) measurements.

\section{Results and Discussions}

3.1. Optical Emission Spectroscopy to Monitor the Organometallic Degradation 
As the plasma emits light, it gives information about the species. Optical emission spectroscopy has been carried out during the plasma treatment (Figure 2). While the intensity of argon lines remains constant along the time, organic species such as $\mathrm{OH}$ or $\mathrm{CN}$ have been identified in $\mathrm{Ar}: \mathrm{O}_{2}$ and $\mathrm{Ar}: \mathrm{NH}_{3}$ discharge respectively, exhibiting a rise and fall evolution along the treatment time (Figure $2 b$ ). As the discharge power increases, the degradation occurs faster, as demonstrated by the shift of the organic line intensity with the time (Figure 2c). Interestingly, this evolution is directly correlated to the degradation of the precursor and the subsequent NPs nucleation (Figure 2d), namely, the OES offers a live view of the process.

(a)

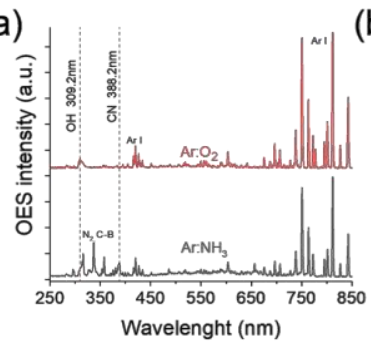

(b)

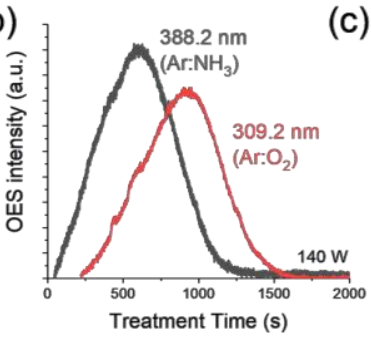

(c)

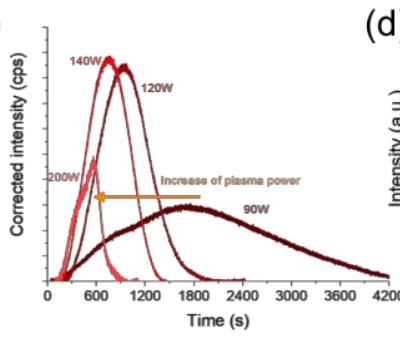

(d)

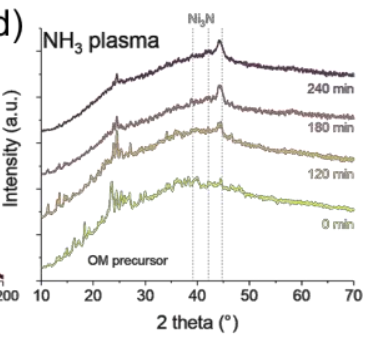

Figure 2. (a) Optical emission spectra at the beginning of the plasma treatment. (b) Evolution of $\mathrm{CN}$ and $\mathrm{OH}$ lines as a function of time in $\mathrm{Ar}: \mathrm{N}_{2}$ and $\mathrm{Ar}: \mathrm{O}_{2}$ discharge. (c) Evolution $\mathrm{CN}$ line intensity as a function of the treatment time, for different plasma power. (d) XRD spectra of $\mathrm{Ni}(\mathrm{acac})_{2}$ mixed with carbon substrate, treated at a different time at $90 \mathrm{~W}$ in $\mathrm{Ar}^{\mathrm{NH}} 3$ discharge.

\subsection{Tailoring the Crystallinity and the Chemistry of the Nanoparticles}

From this process, different types of nanoparticles can be synthesized. Figure 3 gives an insight into the different possibilities. Figure 3a shows the XRD spectra of different metal acetylacetonate, mixed with carbon xerogel substrate, after treatment in Ar: $\mathrm{NH}_{3}$ discharge at $45 \mathrm{mTorr}$. Noble metal elements $(\mathrm{Cu}, \mathrm{Rh}, \mathrm{Pd}, \mathrm{Pt})$ show the formation of metallic nanoparticles, with the formation of the corresponding cubic phase. Transition metals (Fe and $\mathrm{Ni}$ ) lead to the formation of the $\mathrm{Ni}_{3} \mathrm{~N}$ and $\mathrm{Fe}_{3} \mathrm{~N}$ nitride formation, while the manganese leads to the formation of amorphous nanoparticles. For posttransition metal ( $\mathrm{Zn}, \mathrm{Al})$ amorphous NPs are also produced.
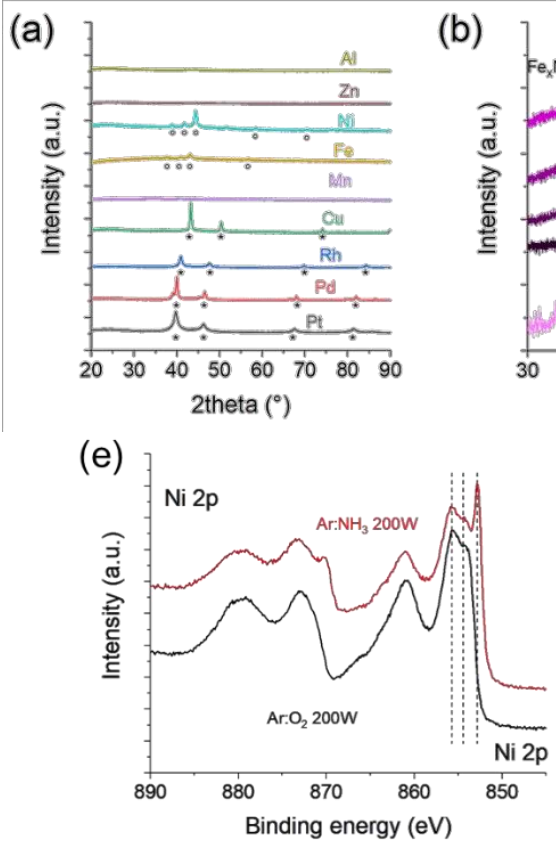
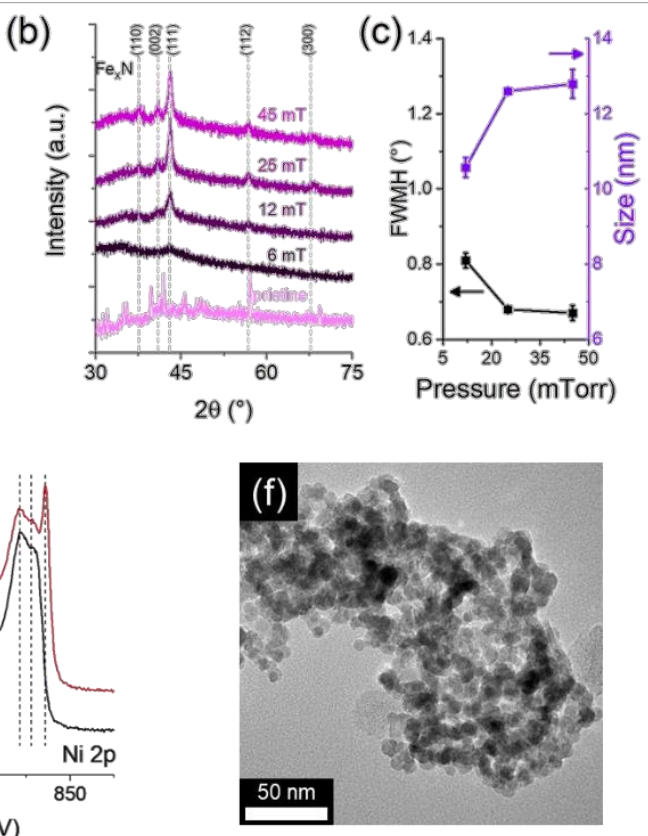
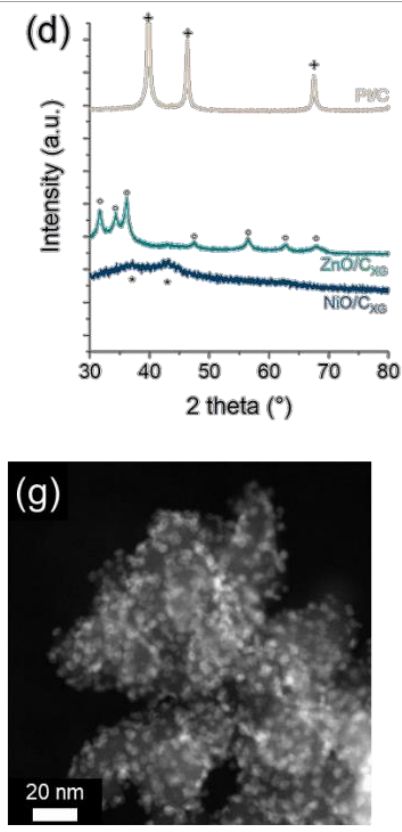

Figure 3. XRD, XPS, and TEM analysis of nanoparticles. (a) XRD spectra of metallic nanoparticles after treatment in ammonia discharge. (b) XRD spectra of FexN nanoparticles synthesized at different 
working pressure and (c) corresponding estimation of the grain size from Debye Scherrer formula. (d) XRD spectra of $\mathrm{NiO}, \mathrm{ZnO}$, and $\mathrm{Pt}$ particles on carbon substrates and $\mathrm{TiO}_{2}$ substrate. (e) XPS spectra of $\mathrm{Ni} 2 \mathrm{p}$ level of nickel nitride and nickel oxide nanoparticles, (f) TEM observation of $\mathrm{ZnO}$ nanoparticles, (g) TEM observation of FexN nanoparticles.

The Figure $3 b$ and $c$ show the influence of the pressure onto the nanoparticle crystallinity: the increase of the working pressure from 6 to 45 mTorr leads to better crystallinity of the NPs; the DebyeScherrer formula estimating an increase from 10 to $13 \mathrm{~nm}$. The increase of the pressure enhances the organometallic degradation due to the higher reactivity of the plasma, coming from higher electron density and collisions [7]. It results in faster nucleation of NPs, and then, a longer "exposure" time of the NPs to the plasma. This longer exposure time favors the nitrogen incorporation and the crystallization of the nanoparticles [3,8,9].

Figure 3d shows the XRD spectra of NPs synthesized in Ar: $\mathrm{O}_{2}$ discharge. Using oxygen discharge, nickel oxide, or zinc oxide nanoparticles are produced, while noble metal (Pt here) still leads to the formation of metallic nanoparticles. For transition metal, the modification of the NPs chemistry via the reactive gas is further confirmed by XPS analysis (Figure 3e): the formation of nickel oxide and nickel nitride is demonstrated in the $\mathrm{Ar}: \mathrm{O}_{2}$ and $\mathrm{Ar}: \mathrm{NH}_{3}$ discharge respectively, with the corresponding Ni 0 , Ni II and Ni III contributions [1,10]. The transmission electron microscopy reveals a homogenous distribution of the nanoparticles onto the powder substrate, for oxide nanoparticles (Figure 3f) as well as for nitride (Figure 3g).

\subsection{Going beyond; Bimetallic Nanoparticles}

The versatility of the process has been extended to bimetallic nanoparticles. In many applications such as catalysis or plasmonic the formation of alloys or bimetallic is required, e.g., for the enhancement of the catalytic activity [11] or the tuning of the plasmonic resonance [12]. In this view, the synthesis of NPs has been performed with the use of two organometallics. Figure 4a presents the XRD spectra of $\mathrm{Pt}$ and $\mathrm{Cu}$ nanoparticles deposited onto $\mathrm{TiO}_{2}$ nanopowder and compared with $\mathrm{PtCu}$ nanoparticles. While the (111) diffraction peak appears at $39.9^{\circ}$ and $43.2^{\circ}$ appears for $\mathrm{Pt}$ and $\mathrm{Cu}$ nanoparticles respectively, a wide peak appears between these two values for the PtCu composition, indicating the possible formation of PtCu alloy [13]. SEM observation (Figure 4b) confirms the formation of the nanoparticles at the $\mathrm{TiO}_{2}$ surface. Further investigations are ongoing to validate the alloy formation.
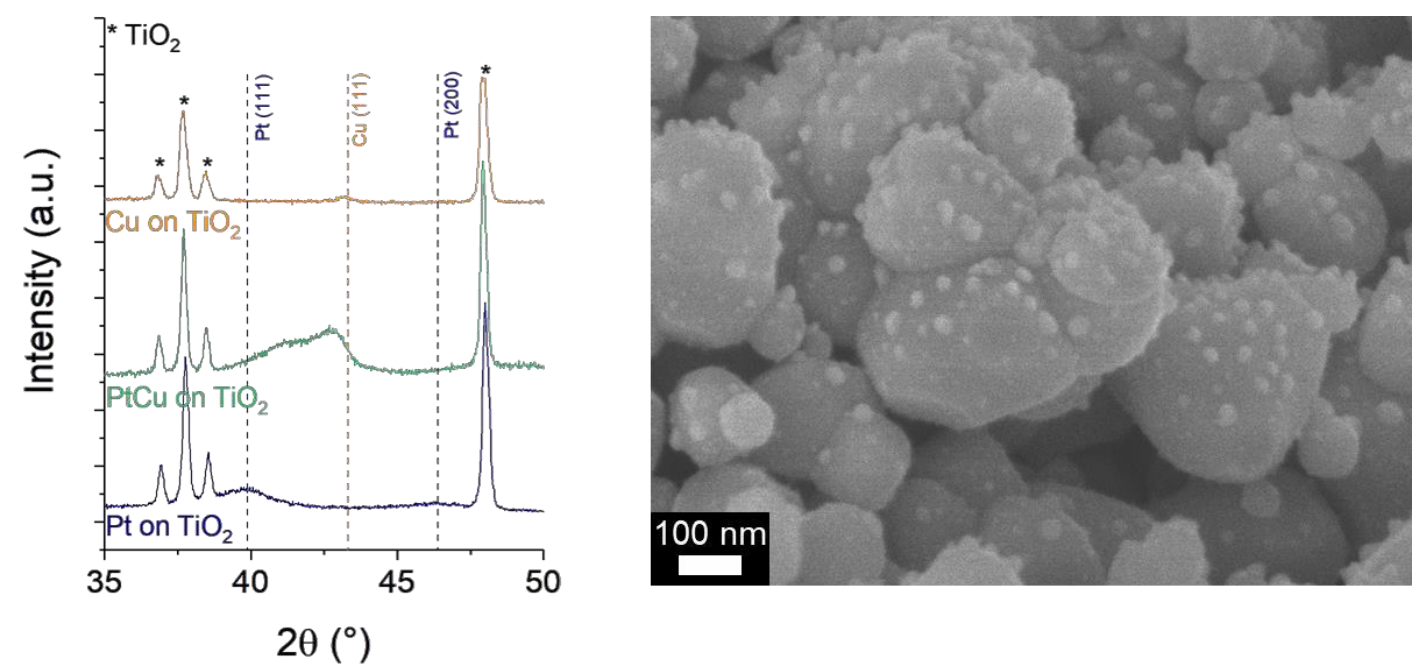

Figure 4. (a) XRD spectra of $\mathrm{Pt}, \mathrm{Cu}$ and $\mathrm{PtCu}$ nanoaprticles deposited onto $\mathrm{TiO}_{2}$ nanopowder. (b) SEM observation of $\mathrm{PtCu}$ nanoparticles onto $\mathrm{TiO}_{2}$ nanopowder.

\section{Conclusions}


An original process is presented to synthesize nanoparticles onto powdery substrates. The method is based on the plasma degradation of solid organometallic (metal acetylacetonate), mixed with the substrate (carbon-based materials, $\mathrm{TiO}_{2}, \ldots$ ). The process is highly versatile as metallic, oxide, or nitride nanoparticle can be produced, amorphous or crystalline, with a size of $\approx 2-15 \mathrm{~nm}$, in a relatively short time $(\approx 1 \mathrm{~h})$. The chemistry of the nanoparticles mainly depends on the choice of the reactive gas (ammonia or oxygen) for transition metal and post-transition metal elements, while noble metal $(\mathrm{Pt}, \mathrm{Pd}, \mathrm{Rh})$ are less sensitive (except $\mathrm{Cu}$ ) and tends to always form metallic nanoparticles. The increases in the working pressure drive the crystallinity of the nanoparticles.

Author Contributions: Conceptualization, E.H, Y.B, M.S.P.; methodology, L.C., F.B., M.D.S.P., E.H., Y.B.; validation, L.C., F.B., M.D.S.P., E.H., Y.B.; formal analysis, L.C., F.B., M.D.S.P., E.H., Y.B..; investigation, L.C., F.B., J.-F.C., M.D.S.P., E.H., Y.B.; data curation, L.C., F.B., J.-F.C., M.D.S.P., E.H., Y.B.; writing-original draft preparation, E.H.; writing - review and editing, all the author.; visualization, E.H..; supervision, Y.B., L.H., J.J.P., S.L.; project administration, L.H., J.-J.P., S.L.; funding acquisition, J.-J.P.

Funding: This research was partially funded by Wallonia Region (Project HYLIFE No. 1410135).

Acknowledgments: The SIAM (Synthesis, Irradiation and Analysis of Materials), PC (Physic Chemistry and Characterisation) and Morph'IM plaforms are acknowledged for XPS, XRD and electronic microscopy analysis respectively

Conflicts of Interest: The authors declare no conflict of interest. The funders had no role in the design of the study; in the collection, analyses, or interpretation of data; in the writing of the manuscript, or in the decision to publish the results.

\section{References}

1. Haye, E.; Busby, Y.; da Silva Pires, M.; Bocchese, F.; Job, N.; Houssiau, L.; Pireaux, J.-J. Low-Pressure Plasma Synthesis of Ni/C Nanocatalysts from Solid Precursors: Influence of the Plasma Chemistry on the Morphology and Chemical State. ACS Appl. Nano Mater. 2018, 1, 265-273, doi:10.1021/acsanm.7b00125.

2 Busby, Y.; da Silva Pires, M.; Haye, E.; Stergiopoulos, V.; Job, N.; Pireaux., J.-J. Versatile Catalyst Materials Fabrication by Low-Pressure Plasma Treatments. In Proceedings of the European Fuel Cell Technology \& Applications Conference; Naples, Italy, 12-15 December 2017.

3. Haye, E.; Soon Chang, C.; Dudek, G.; Hauet, T.; Ghanbaja, J.; Busby, Y.; Job, N.; Houssiau, L.; Pireaux, J.-J. Tuning the Magnetism of Plasma-Synthesized Iron Nitride Nanoparticles: Application in Pervaporative Membranes. ACS Appl. Nano Mater. 2019, 2, 2484-2493, doi:10.1021/acsanm.9b00385.

4 da Silva Pires, M.; Haye, E.; Zubiaur, A.; Job, N.; Pireaux, J.-J.; Houssiau, L.; Busby, Y. Defective Pt$\mathrm{Ni}$ /graphene nanomaterials by simultaneous or sequential treatments of organometallic precursors by lowpressure oxygen plasma. Plasma Process. Polym. 2019, 16, 1800203, doi:10.1002/ppap.201800203.

5. Haye, E.; Job, N.; Wang, Y.; Penninckx, S.; Stergiopoulos, V.; Tumanov, N.; Cardinal, M.; Busby, Y.; Colomer, J.-F.; Su, B.-L.; et al. ZnO/Carbon xerogel photocatalysts by low-pressure plasma treatment, the role of the carbon substrate and its plasma functionalization. J. Colloid Interface Sci. 2020, 570, 312-321, doi:10.1016/j.jcis.2020.03.015.

6. Laurent-Brocq, M.; Job, N.; Eskenazi, D.; Pireaux, J.-J. Pt/C catalyst for PEM fuel cells: Control of Pt nanoparticles characteristics through a novel plasma deposition method. Appl. Catal. B 2014, 147, 453-463, doi:10.1016/j.apcatb.2013.06.021.

7. Gudmundsson, J.T. On the effect of the electron energy distribution on the plasma parameters of an argon discharge: A global (volume-averaged) model study. Plasma Sources Sci. Technol. 2001, 10, 76, doi:10.1088/0963-0252/10/1/310.

8. Puliyalil, H.; Cvelbar, U. Selective Plasma Etching of Polymeric Substrates for Advanced Applications. Nanomaterials 2016, 6, 108, doi:10.3390/nano6060108.

9. Lopez, T.; Mangolini, L. Crystallization Kinetics of Plasma-Produced Amorphous Silicon Nanoparticles. MRS Online Proc. Libr. Arch. 2013, 1536, 213-218, doi:10.1557/opl.2013.755.

10. Payne, B.P.; Grosvenor, A.P.; Biesinger, M.C.; Kobe, B.A.; McIntyre, N.S. Structure and growth of oxides on polycrystalline nickel surfaces. Surf. Interface Anal. 2007, 39, 582-592, doi:10.1002/sia.2565.

11. Zaleska-Medynska, A.; Marchelek, M.; Diak, M.; Grabowska, E. Noble metal-based bimetallic nanoparticles: The effect of the structure on the optical, catalytic and photocatalytic properties. Adv. Colloid Interface Sci. 
2016, 229, 80-107, doi:10.1016/j.cis.2015.12.008.

12 Min, Y.; Wang, Y. Manipulating Bimetallic Nanostructures With Tunable Localized Surface Plasmon Resonance and Their Applications for Sensing. Front. Chem. 2020, 8, doi:10.3389/fchem.2020.00411.

13. Sarkar, A.; Manthiram, A. Synthesis of Pt@Cu Core-Shell Nanoparticles by Galvanic Displacement of Cu by Pt4+ Ions and Their Application as Electrocatalysts for Oxygen Reduction Reaction in Fuel Cells. J. Phys. Chem. C 2010, 114, 4725-4732, doi:10.1021/jp908933r.

Publisher's Note: MDPI stays neutral with regard to jurisdictional claims in published maps and institutional affiliations.

(C) 2020 by the authors. Submitted for possible open access publication under the terms and conditions of the Creative Commons Attribution (CC BY) license (http://creativecommons.org/licenses/by/4.0/). 